\title{
Nodulação de cultivares de soja e seus efeitos no rendimento de grãos ${ }^{1}$
}

\section{Nodulation of soybean cultivars and its effects on grain yield}

\author{
Evandro Martin Brandelero ${ }^{2}$; Clóvis Pereira Peixoto ${ }^{3}$; Ricardo Ralisch ${ }^{4 *}$
}

\section{Resumo}

A adaptação da cultura da soja a um novo ambiente bem como a necessidade da relação simbiótica entre bactéria do gênero Bradyrhizobium e cultivares comerciais de soja, impõe barreiras no processo produtivo de grãos. Como forma de quantificar tais efeitos, este trabalho objetivou avaliar a interação da nodulação e dos componentes morfofisiológicos sobre o rendimento final de grãos de soja nas condições edafoclimáticas do Recôncavo Baiano. O experimento foi conduzido no Campo Experimental da Universidade Federal da Bahia, Cruz das Almas (BA) em delineamento de blocos casualizados, com nove cultivares de soja e quatro repetições. As avaliações foram realizadas no estádio de florescimento pleno com quantificação do número e a massa de nódulos, área foliar, massa da matéria seca das folhas; e outra no estádio de maturação plena, quantificando o rendimento de grãos. Mais de $40 \%$ do rendimento de grão se correlacionaram com os componentes da nodulação dos cultivares de soja, e as cultivares Curió, Conquista e Liderança apresentaram os melhores desempenhos no rendimento de grãos.

Palavras-chaves: Glycine Max, área foliar, correlação, Bradyrhizobium

\begin{abstract}
The adaptations of the soybean crop to a new environment as well as the need of a symbiotic relation among Bradyrhizobium bacteria and the commercial cultivars of soybean impose barriers to the grain productive process. The objective of this work was to evaluate the interaction of nodulation and the morphophysiological components over the final yield of soybean grains in the edaphoclimatical conditions of Recôncavo Baiano Region. The experiment was performed at the Experimental Field of the Federal University of Bahia, Cruz das Almas (BA), with an experimental design of randomized blocks, with nine soybean cultivars and four replications. The evaluations were performed in the stage of full flowering with the quantification of the number and mass of nodules, leaf area, total dry mass; and another evaluation in the full maturation stage, quantifying the grain yield. More than $40 \%$ of the grain yield was correlated to the components of nodulation of the soybean cultivars Curió, Conquista and Liderança cultivars presented the best performances in the yield of grain.
\end{abstract}

Key words: Glycine max, leaf area, correlation, Bradyrhizobium

Parte da Dissertação de Mestrado em Ciências Agrárias na UFBA defendida em 2001.

2 Eng. Agrôn., MSc. Ciências Agrárias e Doutorando Agronomia na UEL. E-mail: evandromartin@yahoo.com.br

3 Eng. Agrôn., MSc. e Dr. em Fisiologia da Produção, Prof. Adjunto na UFTBA. E-mail: cppeixot@ufba.br

4 Eng. Agrôn., MSc. e Dr. em Energia na Agricultura. Prof. Adjunto da UEL. E-mail: ralisch@uel.br

* Autor para correspondência 


\section{Introdução}

A área cultivada com soja (Glycine max L. Merrill), no Brasil, encontra-se em expansão, em especial nas novas fronteiras agrícolas, a exemplo da Região Oeste da Bahia com 870 mil hectares de soja e produção próxima de 2 milhões de toneladas de grãos (COMPANHIA NACIONAL DE ABASTECIMENTO, 2007). Outra Região que possui potencial produtivo é a do Recôncavo Baiano, devido à sua proximidade das vias de escoamento para os portos marítimos, bem como a crescente demanda por farelo de soja para aves e a pecuária leiteira (MENDONÇA, 1998).

A soja é uma cultura que apresenta grande demanda de nutrientes, especialmente o nitrogênio, sendo este extraído predominantemente através da fixação biológica por bactérias fixadoras de nitrogênio (Bradyrhizobium japonicum e B. elkanii), as quais fornecem eficientemente para os grãos de soja cerca de $150 \mathrm{Kg} \mathrm{ha}^{-1}$ de nitrogênio (HUNGRIA et al., 1994) e até $94 \%$ do nitrogênio requerido pelas cultivares mais produtivas pode ser fornecido poresse processo (HUNGRIA et al., 2006). A importância da fixação biológica transformou a inoculação com bactérias nas sementes em uma necessidade tecnológica para atingir ganhos econômicos pela supressão da aplicação de fertilizantes nitrogenados, os quais, se fossem aplicados no plantio, poderiam gerar gastos de aproximadamente US\$ 3 bilhões ao país (MERCANTE, 2006).

A relação simbiótica é específica, devido ambos, bactérias e plantas, fazerem uma troca de sinais moleculares que regulam a expressão de genes para a infecção e desenvolvimento dos nódulos (MÜLLER, 1981; HUNGRIA; VARGAS; ARAÚJO, 1997; LINCOLN; ZEIGER, 2004). Diante disso, vários trabalhos buscam a maximização da eficiência simbiótica na interação entre plantas de soja e estirpes de Bradyrhizobium, visando à obtenção de incrementos na produtividade da cultura (CAMPOS; LANTMANN, 1998; ARAÚJO; HUNGRIA, 1999; MOREIRA; CARVALHO; EVANGELISTA, 1999; MERCANTE, 2006; SOUZA et al., 2008).
Contudo, existe grande variabilidade entre as estirpes que nodulam a soja (CARVALHO, 2003) quanto à eficiência do processo simbiótico (ARAÚJO; HUNGRIA, 1999), o que gera diferentes interações entre bactérias e genótipos de plantas de soja (BOHRER; HUNGRIA, 1998).

Bohrer e Hungria (1998) verificaram diferenças marcantes entre as cultivares quanto ao potencial de nodulação e fixação de nitrogênio, e constataram que a quantificação da massa seca da parte aérea é um bom parâmetro para a seleção das simbioses mais promissoras de soja. O efeito da parte aérea e do sistema radicular sobre a nodulação de soja foram avaliados por Sheng e Harper (1997), os quais constataram que as folhas são órgãos que dominam a regulação da produção de sinal para nodulação em soja.

Diante do exposto, o objetivo do trabalho foi avaliar o efeito da nodulação no rendimento de grãos de soja de nove cultivares de soja nas condições edafoclimáticas do Recôncavo Baiano.

\section{Material e métodos}

O experimento foi conduzido no Campo Experimental da Universidade Federal da Bahia, no município de Cruz das Almas (BA), situado no Recôncavo Baiano (1240'19" S e 3906'22" $\mathrm{O}, 220 \mathrm{~m})$. O clima é tropical quente úmido, classificado como Aw a Am. Segundo Almeida (1991), a pluviosidade média anual é de $1.224 \mathrm{~mm}$, e a temperatura média anual é de $24,5^{\circ} \mathrm{C}$ e umidade relativa de $80 \%$. O solo da área experimental é classificado como Latossolo Amarelo álico coeso, "A" moderado, textura franco-argiloso e relevo plano (REZENDE, 2000).

Anteriormente à semeadura da soja foi feita análise química do solo (Tabela 1), para que se procedesse à correção de acidez e fertilidade seguindo as recomendações técnicas da cultura e posterior incorporação dos corretivos e fertilizantes através de uma gradagem. 
Tabela 1. Análise química ${ }^{1}$ do solo da área experimental na profundidade de 0-20 cm.

\begin{tabular}{|c|c|c|c|c|c|c|c|c|c|c|c|}
\hline $\begin{array}{l}\mathbf{p H} \\
\mathrm{CaCl}_{2}\end{array}$ & $\begin{array}{l}\text { M.O. } \\
\mathrm{g} \mathrm{dm}^{-3}\end{array}$ & $\begin{array}{l}\mathbf{P} \\
\mathrm{mg} \mathrm{dm^{-3 }}\end{array}$ & $\begin{array}{l}\mathbf{K} \\
\mathrm{cmol}_{\mathrm{c}}\end{array}$ & $\begin{array}{l}\text { Ca } \\
\mathrm{m}^{-3}\end{array}$ & Mg & $\mathrm{Ca}+\mathrm{Mg}$ & Al & $\mathbf{H}+\mathbf{A l}$ & $\mathbf{S}$ & CTC & $\begin{array}{l}\mathbf{V} \\
\%\end{array}$ \\
\hline 5,2 & 14,64 & 10,00 & 0,22 & 1,8 & 1,2 & 3,0 & 0,10 & 2,42 & 3,26 & 5,68 & 57,4 \\
\hline
\end{tabular}

${ }^{1}$ Laboratório de Análises Químicas de Solo da Embrapa Mandioca e Fruticultura.

As sementes foram tratadas com $100 \mathrm{~g}$ do fungicida Benomil por $100 \mathrm{~kg}$ de sementes. Posteriormente as sementes foram inoculadas com Bradyrhizobium japonicum com a mistura proporcional das estirpes SEMIA 587 e SEMIA 5019, estabelecendo-se uma população do solo de $1 \times 10^{8}$ células $\mathrm{g}^{-1}$, oriundas do Laboratório de Microbiologia da Embrapa Soja e recomendados para as condições climáticas do Oeste da Bahia. A semeadura foi realizada manualmente adicionandose $50 \%$ a mais de sementes, efetuando-se o desbaste quinze dias após, de forma a garantir a densidade de 15 plantas por metro linear. As principais condições climáticas pelas quais evoluiu o ciclo dos cultivares encontram-se na Figura 1.

As cultivares de soja avaliadas foram: Conquista (MG/BR46), Curió (MT/BR52), Celeste (BRS60),
Liderança (MG/BRS66), Paiaguás (MT/BR45), Parecis (MT/BR50), Tucano (MT/BR53), Uirapurú (MT/BR55) e Rio Vermelho (EMGOPA315).

$\mathrm{O}$ experimento foi conduzido no delineamento de blocos casualizados, com nove cultivares e quatro repetições. A densidade de plantio foi de 15 plantas por metro linear, sendo que cada unidade experimental foi composta de oito linhas de plantio com 5,0 m de comprimento, distanciadas $0,50 \mathrm{~m}$ uma das outras, sendo três fileiras para avaliar no estádio de maturação plena o rendimento de grãos; e duas fileiras para avaliar no estádio de pleno florescimento para o número e massa de nódulos, área foliar, massa da matéria seca das folhas. As outras três fileiras serviram de bordadura entre as limitações da parcela.

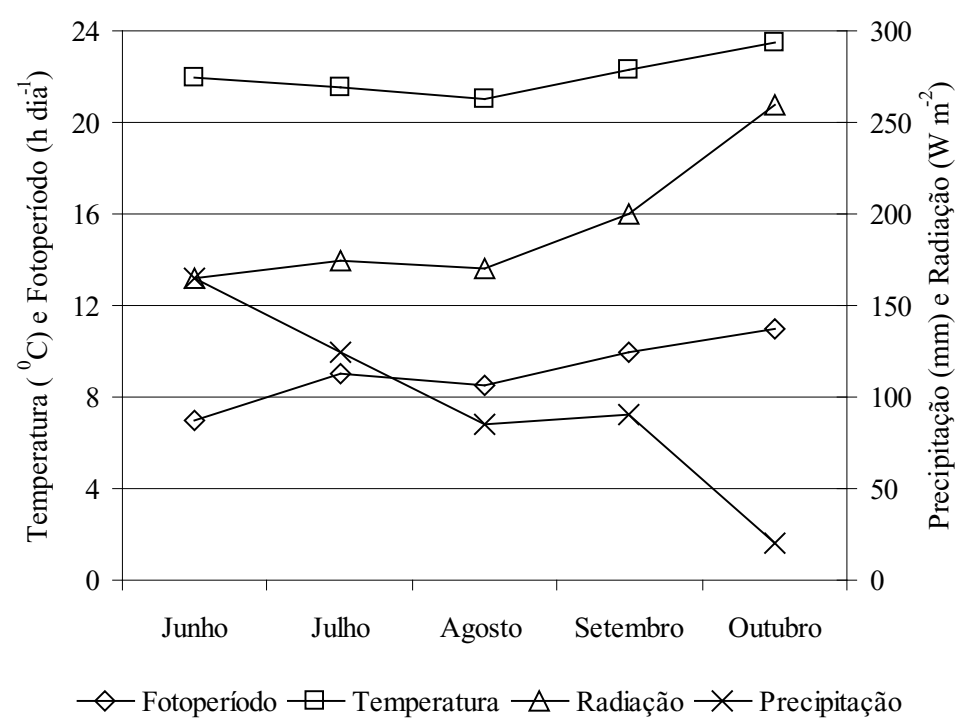

Figura 1. Valores médios mensais da temperatura do ar; fotoperíodo; radiação solar e precipitação total nas condições climáticas de Cruz das Almas - BA. 
A avaliação da nodulação entre os cultivares de soja foi realizado no estádio de pleno florescimento, em dez plantas por parcela. As plantas foram coletadas com o cuidado de manter o volume de solo pré-estabelecido para cada planta de $0,032 \mathrm{~m}^{3} \mathrm{com}$ dimensões de 0,4 $\left(\mathrm{L}_{1}\right)$ x 0,4 $\left(\mathrm{L}_{2}\right)$ x 0,2 $(\mathrm{H})$ coletadas com auxílio da pá-de-corte, centralizando a planta no quadro $0,4\left(\mathrm{~L}_{1}\right) \times 0,4\left(\mathrm{~L}_{2}\right) \mathrm{m}$. Posteriormente foram separados raízes, nódulos e solo da amostra, com auxílio de peneira com malha de $3 \mathrm{~mm}$ e água corrente para limpeza do solo aderido às partes vegetais. Após drenagem do excesso de água das plantas, os nódulos foram acondicionados em sacos de papel identificados com suas respectivas partições (nódulos, raízes, haste, folhas e pecíolos), e realizou-se contagem do número de nódulos por planta. Em etapa seguinte as amostras foram levadas para secagem em estufa a $65^{\circ} \mathrm{C}$ até obter peso constante e aferiram-se suas massas.

No estádio de maturação plena $\left(\mathrm{R}_{8}\right)$, avaliou-se o rendimento de grãos de cada parcela, transformandoos para rendimento por hectare, sendo ambos corrigidos para a umidade de $13 \%$.

Os resultados foram submetidos à análise de variância e as médias foram comparadas pelo teste de Tukey a 5\% de probabilidade. Para melhor analisar a interação das variáveis efetuou-se a correlação simples (r) dos dados obtidos através do Teste t; e para interpretação das correlações, seguiram-se as recomendações de Peixoto (1999).

\section{Resultados e discussões}

Os valores de nodulação mostram maior número de nódulos ocorrido na cultivar Liderança, diferindo significativamente das cultivares Conquista, Curió, Celeste e Paiaguás, apresentando esta última a menor média no grupo. Estes resultados estão próximos aos encontrados por Campos e Lantmann (1998), que trabalharam com cultivares de soja no estado do
Paraná com as mesmas estirpes para a nodulação. Porém, o presente resultado está abaixo dos encontrados por Araújo e Hungria (1999), os quais obtiveram valores que chegaram a 41,7 unidades de nódulos por planta nas condições climáticas do Paraná. Esta variabilidade de resultados de número de nódulos entre as cultivares está relacionada a caracteres intrínsecos (genéticos) das cultivares avaliados conforme resultados encontrados por Bohrer e Hungria (1998).

Constatam-se diferenças significativas quanto à massa da matéria seca dos nódulos (Tabela 2) tendo a maior produção a cultivar Rio Vermelho diferindo significativamente das cultivares Conquista, Curió, Celeste, Paiaguás, Parecís e Uirapuru. Estes resultados estão bem acima dos encontrados por Campos e Lantmann (1998), os quais obtiveram média de $67 \mathrm{mg}$ planta $^{-1}$ de massa da matéria seca dos nódulos no Estado do Paraná. Araújo e Hungria (1999) obtiveram média de $140 \mathrm{mg} \mathrm{planta}^{-1}$ de massa da matéria seca dos nódulos, valores próximos aos encontrados no presente trabalho, demonstrando não haver restrições para o desenvolvimento da nodulação nas condições agroecológicas de Cruz das Almas - BA na época avaliada.

Os resultados de massa da matéria seca das folhas e a área foliar (Tabela 2) tiveram comportamentos similares entre si, devido, possivelmente, às suas estreitas correlações. Observaram-se diferenças significativas entre as cultivares quanto à massa da matéria seca e a área foliar (Tabela 2), tendo a cultivar Liderança as maiores médias de massa da matéria seca da folha e área foliar, diferindo de Conquista, Curió, Celeste e Tucano. Estes resultados condizem com os de Peixoto (1999), que trabalho a campo no Estado de São Paulo, e estão acima dos encontrados por Bohrer e Hungria (1998), trabalhando com 152 cultivares de soja obtendo a maior média do experimento $\left(2,19 \mathrm{~g} \mathrm{pl}^{-1}\right)$ na cultivar J-200 na condição de casa de vegetação no Estado do Paraná. 
Tabela 2. Valores médios da nodulação (número e massa matéria seca), massa da matéria seca da folha (M.M.S.F.), área foliar (A.F.) em pleno florescimento $\left(R_{2}\right)$ e rendimento de grãos em maturação plena $\left(R_{8}\right)$ de nove cultivares de soja, Cruz das Almas - BA, 2000.

\begin{tabular}{|c|c|c|c|c|c|}
\hline \multirow{3}{*}{ Cultivares } & \multicolumn{4}{|c|}{ Florescimento pleno $\left(\mathbf{R}_{2}\right)$} & \multirow{3}{*}{$\begin{array}{c}\text { Produtividade }\left(\mathrm{R}_{8}\right) \\
\text { Rendimento } \\
\mathrm{Kg} \mathrm{ha}^{-1}\end{array}$} \\
\hline & \multicolumn{2}{|c|}{ Nodulação } & \multirow{2}{*}{$\begin{array}{c}\text { M.M.S.F. } \\
\mathrm{g} \mathrm{pl}^{-1}\end{array}$} & \multirow{2}{*}{$\begin{array}{c}\text { A.F. } \\
\mathbf{d m}^{2} \mathbf{p l}^{-1}\end{array}$} & \\
\hline & $\mathbf{n}^{0} \mathbf{p l}^{-1}$ & $\mathrm{mg} \mathrm{pl}^{-1}$ & & & \\
\hline Conquista & $16,3 \mathrm{bc}$ & $140,5 \mathrm{bc}$ & $1,39 \mathrm{~b}$ & $2,8 \mathrm{~b}$ & $1.883 \mathrm{a}$ \\
\hline Curió & $14,2 \mathrm{bc}$ & $149,4 \mathrm{bc}$ & $1,59 \mathrm{~b}$ & $3,2 \mathrm{~b}$ & $1.945 \mathrm{a}$ \\
\hline Celeste & $15,7 \mathrm{bc}$ & $166,6 \mathrm{~b}$ & $1,32 \mathrm{~b}$ & $2,6 \mathrm{~b}$ & $1.156 \mathrm{~d}$ \\
\hline Liderança & $23,4 \mathrm{a}$ & $239,1 \mathrm{a}$ & $2,57 \mathrm{a}$ & $5,1 \mathrm{a}$ & $1.778 \mathrm{ab}$ \\
\hline Paiaguás & $13,3 \mathrm{c}$ & $167,2 \mathrm{~b}$ & $1,67 \mathrm{ab}$ & $3,3 \mathrm{ab}$ & $1.193 \mathrm{~cd}$ \\
\hline Parecis & $21,6 \mathrm{a}$ & $158,6 \mathrm{~b}$ & $1,79 \mathrm{ab}$ & $3,6 \mathrm{ab}$ & $1.500 \mathrm{bc}$ \\
\hline Tucano & $21,3 \mathrm{a}$ & $203,8 \mathrm{ab}$ & $1,49 \mathrm{~b}$ & $2,9 \mathrm{~b}$ & $1.241 \mathrm{~cd}$ \\
\hline Uirapuru & $18,1 \mathrm{abc}$ & $177,1 \mathrm{~b}$ & $1,69 \mathrm{ab}$ & $3,4 \mathrm{ab}$ & $1.370 \mathrm{~cd}$ \\
\hline Rio Vermelho & $19,5 \mathrm{ab}$ & 247,4 a & $1,79 a b$ & $3,8 \mathrm{ab}$ & $1.219 \mathrm{~cd}$ \\
\hline C.V. $(\%)$ & 20,75 & 22,27 & 22,36 & 22,1 & 9,55 \\
\hline D.M.S. & 3,73 & 38,86 & 1,02 & 1,9 & 329,69 \\
\hline
\end{tabular}

Obs: Médias seguidas por letras distintas na coluna diferem entre si pelo teste de Tukey a 5\% de significância.

Foram constatadas diferenças estatísticas entre as médias de rendimento de grãos das cultivares (Tabela 2), tendo a Curió (1.945 $\left.\mathrm{kg} \mathrm{ha}^{-1}\right)$ e a Conquista $\left(1.883 \mathrm{~kg} \mathrm{ha}^{-1}\right)$ as maiores produtividades de grãos, diferindo estatisticamente das demais, a exceção de Liderança (1.778 $\left.\mathrm{kg} \mathrm{ha}^{-1}\right)$. Já a menor as menores produtividades foram apresentadas por Celeste (1.156 kg ha' $\left.{ }^{-1}\right)$, seguida de Paiaguás (1.193 $\left.\mathrm{kg} \mathrm{ha}{ }^{-1}\right)$, Rio Vermelho (1.219 $\left.\mathrm{kg} \mathrm{ha}^{-1}\right)$, Tucano (1.241 kg ha-1) e Uirapuru (1.370 Kg ha $\left.{ }^{-1}\right)$.

Numa visão conjunta dos dados, observa-se na Tabela 2 que a cultivar Liderança apresentou notável desempenho por apresentar as maiores médias de número de nódulos, massa da matéria seca dos nódulos e das folhas e do rendimento de grãos, demonstrando potencial produtivo para o município de Cruz das Almas na época estudada.

A produtividade média da soja na Região Oeste do Estado da Bahia é de $2.400 \mathrm{~kg} \mathrm{ha}^{-1}$ (SECRETARIA DE AGRICULTURA DO ESTADO DA BAHIA,
2007), valores estes não alcançados no presente estudo, nas condições agroecológicas de Cruz das Almas - BA. Essa baixa produtividade obtida, possivelmente está relacionada às limitações fotoperiódicas, agravando-se com o déficit hídrico ao longo do ciclo das cultivares (Figura 1). Segundo Peixoto (1999) a deficiência hídrica reduz severamente o rendimento, seja pelo abortamento de grãos, ou pela formação de grãos mais leves, uma vez que interfere negativamente no enchimento de grãos. No entanto, cultivares como Curió, Conquista e Liderança, apresentaram os melhores potenciais de rendimento de grãos para esta localidade do Recôncavo Baiano.

Para melhor compreender a interação do rendimento de grãos com a nodulação (número e massa da matéria seca) e a massa da matéria das folhas da planta como sua respectiva área foliar, procedeu-se a análise estatística de correlação simples (r) apresentados na Tabela 3. 
Tabela 3. Estimativa dos coeficientes de correlação (r) da nodulação (número e massa da matéria seca dos nódulos), massa da matéria seca total da planta em pleno florescimento com o rendimento de grãos de nove cultivares de soja em Cruz das Almas - BA, 2000.

\begin{tabular}{ccccc}
\hline Variáveis & Número nódulos & Massa seca nódulos & Massa seca das folhas & Área foliar \\
\hline Rendimento de grãos & $0,42^{*}$ & $0,41^{*}$ & $0,36^{*}$ & 0,26 \\
\hline
\end{tabular}

* Significativo pelo teste $\mathrm{t}$ ao nível de $5 \%$ de probabilidade.

A correlação foi estatisticamente significativa e apresentou valores altos para o rendimento de grãos das cultivares de soja sobre os componentes da nodulação (número e massa matéria seca) demonstrando que mais de $40 \%$ dos resultados do rendimento se correlacionaram com a nodulação, seguidos de $36 \%$ para massa seca das folhas das plantas. Desta forma, os resultados demonstram que a nodulação foi a que melhor interagiu com rendimento de grãos, sendo que a área foliar apresentou baixa correlação (26\%) e não significativa. Estes resultados indicam que a nodulação em florescimento pleno está diretamente ligada à fixação simbiótica do nitrogênio para a produção de grãos, devido à grande demanda nutricional para a produção de proteína no grão, que representa valores ao redor de $46 \%$ do peso. Esta lógica poderá ser demonstrada com a cultivar Liderança, que apresentou o maior número de nódulos, a segunda maior produção de massa da matéria seca dos nódulos e a terceira maior produtividade de grãos. Segundo Souza et al. (2008), em avaliação qualitativa e quantitativa da microbiota do solo e da fixação biológica do nitrogênio pela soja em diferentes localidades e épocas, constataram que os dados das massas dos nódulos e da parte aérea são adequados para avaliar o crescimento e o desempenho simbiótico da soja, confirmando os resultados encontrados do presente trabalho.

\section{Conclusões}

As cultivares Curió, Conquista e Liderança, apresentam os melhores desempenhos do rendimento de grãos nas condições agroecológicas estudadas.
Constatou-se que a nodulação tem estreita relação com o rendimento final de grãos entre as cultivares de soja estudadas.

\section{Agradecimentos}

A CAPES pela concessão da bolsa de estudo e a Dra. Mariângela Hungria da Embrapa - soja pela doação das estirpes de Bradyrhizobium.

\section{Referências}

ALMEIDA, O. A. Informações metereológicas do CNPMandioca e Fruticultura tropical. Cruz das Almas/BA: EMBRAPA-CNPMF. 1991. 35p. (EMBRAPA-CNPMF. Documentos, 34).

ARAÚJO, F. F.; HUNGRIA, M. Nodulação e rendimento de soja co-infectada com Bacillussubtilis e Bradyrhizobium japonicum / Bradyrhizobium elkanii. Pesqisa AgropecuáriaBrasileira, Brasília, v. 34, n. 9, p. 1633-1643, set. 1999.

BOHRER, T. R. J.; HUNGRIA, M. Avaliação de cultivares de soja quanto à fixação biológica do nitrogênio. Pesquisa Agropecuária Brasileira, Brasília, v. 33, n. 6, p. 937-953, jun. 1998.

CAMPOS, R. J.; LANTMANN, A. F. Efeitos de micronutrientes na fixação biológica do nitrogênio e produtividade da soja. Pesquisa Agropecuária Brasileira, Brasília, v. 33, n. 8, p. 1245-1253, ago. 1998.

CARVALHO, F. G. Variabilidade de isolados de estirpes de Bradyrhizobium ssp recomendadas para a cultura da soja. 2003. Tese (Doutorado em Ciências do solo) - Universidade Federal do Rio Grande do Sul. Porto Alegre, 2003.

COMPANHIA NACIONAL DE ABASTECIMENTO - CONAB. Estimativa da safra grãos 06/2007 para o Estado da Bahia. Brasília: Conab, 2007. 
HUNGRIA, M.; CAMPO, R. J.; MENDES, I. C.; GRAHAM, P. H. Contribution of biological nitrogen fixation to the $\mathrm{N}$ nutrition of grain crops in the tropics: the success of soybean (Glycine max (L.) Merr.) in South America. In: SINGH, R. P.; SHANKAR, N.; JAIWAL, P. K. (Ed.). Nitrogen nutrition and sustainable plant productivity. Houston: Studium Press, LLC, 2006. p. 4393.

HUNGRIA, M.; VARGAS, M. A. T.; ARAUJO, R. S. Fixação biológica do nitrogênio em feijoeiro. In: VARGAS, M. A. T.; HUNGRIA, M. (Ed.). Biologia dos solos de cerrados. Planaltina: EMBRAPA-CPAC, 1997. p. 187-294.

HUNGRIA, M.; VARGAS, M. A. T.; SUHET, A. R.; PERES, J. R. R. Fixação biológica do nitrogênio na soja. In: ARAÚJO, R. S.; HUNGRIA, M. (Ed.). Microorganismos de importância agrícola. Brasília: Embrapa-SPI, 1994. p. 9-89.

LINCOLN, T.; ZEIGER, E. Fisiologia vegetal. Porto Alegre: Artmed, 2004. p. 95-112.

MENDONÇA, J. O. A agricultura e a agroindústria no recôncavo. Bahia Agrícola, Salvador, v. 2, n. 3, p. 23-29, nov. 1998.

MERCANTE, F. M. Uso de inoculante garante economia de 3 bilhões de dólares na cultura da soja no país. Disponível em: <http://www.embrapa.br/noticias/ artigos>. Acesso em: 10 dez. 2006.

MOREIRA, A.; CARVAlHO, J. G.; EVANGELISTA, A. R. Influência da relação cálcio: magnésio do corretivo na nodulação, produção e composição mineral da alfafa.
Pesquisa Agropecuária Brasileira, Brasília, v. 34, n. 2, p. 249-255, fev. 1999.

MÜLLER, L. Fixação simbiótica do nitrogênio. In: MIYASAKA, S.; MEDINA, J.C. A soja no Brasil. Campinas: ITAL, 1981. p. 401-414.

PEIXOTO, C. P. Análise de crescimento e rendimento de três cultivares de soja em três épocas de semeadura e três densidades de plantas. 1999. Tese (Doutorado em Fitotecnia) - Escola Superior de Agricultura "Luiz de Queiroz”, Universidade de São Paulo, Piracicaba, 1999.

REZENDE, J. O. Solos coesos dos tabuleiros costeiros: limitações agrícolas e manejo. Salvador: SEAGRI-SPA, 2000. (Série estudos agrícolas).

SECRETARIA DE AGRICULTURA DO ESTADO DA BAHIA - SEAGRI. Agricultura na Bahia. Salvador: SEAGRI, 2007.

SHENG, C.; HARPER, J. E. Shoot versus root signal lnvolvement in nodulation and vegetative growth in wild-type and hypernodulating soybean genotypes. Plant Physiology, Lancaster, v. 11, n. 3, p. 825-831, 1997.

SOUZA, R. A.; HUNGRIA, M.; FRANCHINI, J. C.; CHUEIRE, L. M. O.; BARCELLOS, F. G.; CAMPO R. J. Avaliação qualitativa e quantitativa da microbiota do solo e da fixação biológica do nitrogênio pela soja. Pesquisa Agropecuária Brasileira, Brasília, v. 43, n. 1, p. 71-82, 2008.

VARGAS, M. A. T.; HUNGRIA, M. Fixação biológica do nitrogênio em soja. In: VARGAS, M. A. T.; HUNGRIA, M. (Ed.). Biologia dos solos de cerrados. Planaltina: EMBRAPA-CPAC, 1997. p. 295-360. 
